\title{
BMJ Open Effects associated with the use of healthcare for eating disorders by women in the community: a longitudinal cohort study
}

\author{
Nicol Holtzhausen, ${ }^{1}$ Haider Mannan, ${ }^{1}$ Nasim Foroughi, ${ }^{1}$ Phillipa Hay ${ }^{1}{ }^{1,2}$
}

To cite: Holtzhausen $\mathrm{N}$, Mannan $\mathrm{H}$, Foroughi N, et al. Effects associated with the use of healthcare for eating disorders by women in the community: a longitudinal cohort study. BMJ Open 2020;10:e033986. doi:10.1136/ bmjopen-2019-033986

- Prepublication history for this paper is available online. To view these files, please visit the journal online (http://dx.doi. org/10.1136/bmjopen-2019033986).

Received 31 August 2019

Revised 01 May 2020

Accepted 13 July 2020
Check for updates

(c) Author(s) (or their employer(s)) 2020. Re-use permitted under CC BY-NC. No commercial re-use. See rights and permissions. Published by BMJ.

${ }^{1}$ Translational Health Research Institute, School of Medicine, Western Sydney University, Penrith South, New South Wales, Australia

${ }^{2}$ Campbelltown Hospital Mental Health, South West Sydney Local Health District, Campbelltown, New South Wales, Australia

Correspondence to

Professor Phillipa Hay;

P.Hay@westernsydney.edu.au

\section{ABSTRACT}

Objectives This study examined formal and informal healthcare use (HCU) in community women with disordered eating, and associations of HCU with mental health-related quality of life (MHRQoL), psychological distress, mental health literacy (MHL) and eating disorder (ED) symptoms over time.

Hypothesis We hypothesised that HCU would lead to improvement in ED symptom severity, MHRQoL, MHL and psychological distress.

Design, setting, participants Data were from years 2, 4 and 9 of a longitudinal cohort of 443 community women (mean age 30.6, SE 0.4 years) with a range of ED symptoms, randomly recruited from the Australian Capital Territory electoral role or via convenience sampling from tertiary education centres. Data were collected using posted/emailed self-report questionnaires; inclusion criteria were completion of the HCU questionnaire at time point of 2 years (baseline for this study). HCU was measured using a multiple-choice question on help seeking for an eating problem. To test the effect of HCU over time on MHRQoL (Short Form-12 score), psychological distress (Kessler Psychological Distress Scale score), ED symptom severity (Eating Disorder Examination Questionnaire score) and ED-MHL, linear or logistic mixed-effects regression analyses were used. Results $20 \%$ of participants sought ED-specific help at baseline; more than half of participants sought help that was not evidence based. HCU at baseline was significantly associated with improved MHRQoL and ED symptom severity and decreased psychological distress over time (Cohen's $d$ all $>0.3$, ie, small). HCU was not significantly associated with MHL over time. The predictive ability of the fitted models ranged from $32.18 \%$ to $42.42 \%$ for psychological distress and MHL treatment, respectively. Conclusions Formal and informal HCU were associated with small improvements in ED symptoms, MHRQoL and psychological distress but not with improved MHL. Informal services in ED management should be investigated further along with efforts to improve ED-MHL.

\section{INTRODUCTION}

\section{Background}

Common feeding and eating disorders (EDs) are binge ED (BED), anorexia nervosa $(\mathrm{AN})$ and bulimia nervosa $(\mathrm{BN}){ }^{1}$

\section{Strengths and limitations of this study}

The study had an adequate sample size and power to detect significant effect of healthcare use on main outcomes but not on mental health literacy.

- The study used a longitudinal design that allows for causal inferences.

The study participants were recruited from the community and thus less subjected to selection bias than if recruited from a clinical population.

- There was moderate attrition over time and thus a need for imputation of data.

- The study did not compare the outcomes of different types of help seeking.

The most common ED worldwide is BED with global mean lifetime prevalence of $2.8 \%$ in women. ${ }^{2} \mathrm{AN}$ and BN each carry a global mean lifetime prevalence of $1.4 \%$ and $1.9 \%$, respectively. ${ }^{2}$

The burden of disease associated with these EDs is considerable and includes physical, psychosocial and economic impairments. ${ }^{3-6}$ Mental health disorders in particular have been found to occur at higher rates in women with EDs, compared with community samples. ${ }^{7-9}$ Specifically, depression and anxiety disorders are more prevalent in those with disordered eating ${ }^{10}$ as are suicide and self-harm behaviour. ${ }^{11}{ }^{12}$ Individuals engaging in disordered eating behaviours (eg, binge eating, purging or strict dieting/fasting for weight/shape control) are more likely to experience high levels of psychological distress ${ }^{13}$ and have impaired adaptive function. ${ }^{14}$ Those with EDs also often report lower health-related quality of life, ${ }^{15}{ }^{16}$ proportionate to the severity of the illness. ${ }^{17} 18$ While burden of these problems is high, many people with an ED do not seek formal healthcare and there is a known gap with regards to evidence-based treatment seeking. ${ }^{19}$ 


\section{Healthcare use in people with EDs}

Evidence-based treatments for EDs include specific psychological therapies, medical care of physical sequelae of EDs such as starvation and specialised inpatient or day patient programmes. ${ }^{20}{ }^{21}$ Health services offering access to these evidence-based treatments for individuals with EDs include primary care physicians, psychologists and psychiatrists; other sources of formal and informal healthcare may include community support groups, dietitians, nutritionists and counselling services. Individuals with EDs may also seek social support, which may have a positive influence on recovery ${ }^{22} 23$ and could play a role in encouraging professional help seeking. ${ }^{24}$ However, there may be barriers to social help seeking, including social stigma, a lack of belief in the ability of peers and family members to empathise or provide support and a fear of burdening others ${ }^{25}$ and where there is perceived low quality of social support. ${ }^{2627}$

While individuals with EDs engage with healthcare more than those without, ${ }^{28}{ }^{29}$ this is most often not for their ED. ED-related healthcare use (HCU) is thus uncommon, and seeking help that is evidence based is even less common. ${ }^{30-33}$ A systematic review by Hart $e t$ al found that only $23.2 \%$ of community cases with a clinically diagnosable ED sought appropriate ED-specific help. ${ }^{19}$ A consequence of this treatment gap is that, despite increased HCU, ED sufferers may not experience improvement in their ED symptomatology. ${ }^{34}$

\section{The treatment gap and mental health literacy}

There are several reasons for this treatment gap. They include barriers such as social stigma,${ }^{35}$ cost,${ }^{36}$ poor insight into eating pathology ${ }^{37}$ and delays in seeking treatment. ${ }^{38}$ In addition, people with EDs have a higher burden of disease from other mental health conditions ${ }^{38-41}$ and are more likely to access non-ED-specific mental healthcare for these. ${ }^{29} 32$

Mental health literacy (MHL) is considered an important contributor to the treatment gap in $\mathrm{EDs}^{37}$ as well as mental illness more broadly. ${ }^{43}$ MHL refers to knowledge about mental disorders, which aid their recognition, management and prevention. ${ }^{44}$ MHL regarding $\mathrm{BN}$ and other EDs has been investigated in women with and without ED symptoms, where those with EDs and those at high risk had poorer MHL than those at low risk for EDs. ${ }^{45}$ Furthermore, a brief intervention to improve MHL has been shown to improve health-related quality of life in community women. ${ }^{37}$ However, at longer term follow-up, ${ }^{36}$ qualitative analyses revealed ongoing problems with HCU and accessing evidence-based treatment in this cohort.

\section{Objectives/aims and hypotheses}

Despite extensive investigation of barriers to and patterns of help-seeking, ${ }^{19}$ and the known effectiveness of ED treatments, ${ }^{2021}$ few studies have investigated varying levels and types of HCU and their outcomes in relation to MHL in community samples of individuals with disordered eating. This study thus aimed to examine the extent and type of HCU and the outcomes of this over time. We hypothesised that HCU would lead to improvement in ED symptom severity and mental health-related quality of life (MHRQoL) and decreased psychological distress. We also hypothesised that HCU would lead to improved MHL. We did not hypothesise at which time point this would be most pronounced as this question was explorative.

\section{METHODS AND MATERIALS}

\section{Participants and overall design}

Participants in this study consisted of pooled data from two cohorts recruited for a longitudinal study on Women's Eating and Health Literacy. The first cohort was recruited using random selection of 10000 women aged 18-42 from the Australian Capital Territory (ACT) electoral roll; $52.6 \%$ of these returned the initial survey, 324 of whom met ED screening criteria. Eating disorder examination (EDE) interviews with these women identified 185 clinically symptomatic women, 122 of whom agreed to longitudinal study participation. ${ }^{46}$ The second cohort was a convenience sample drawn from 706 ED symptomatic and subclinical women recruited from four higher education centres including university and nonuniversity institutions in two states (Queensland and Victoria) using print and email advertisements as well as direct recruitment. Due to the public advertisements on campuses, it was not known how many may have seen the advertisement and therefore the response rate was unable to be ascertained. Of participants who returned surveys at baseline, 448 (54.1\%) completed follow-up at year 2, 434 $(52.4 \%)$ completed follow-up at year 4 and 264 (44.0\%) completed follow-up at year $9 .{ }^{47}$ For the purposes of the present study, data were pooled in order to increase the proportion of participants with high levels of ED symptoms (ie, those in the first cohort) and increase the sample size for analyses. Data were from assessment time points at years 2, 4 and 9, where the HCU and MHL were both included; data were drawn from all participants who completed the year-2 survey $(n=448$; see figure 1$)$.

\section{Measures}

Health Care Use (HCU)

ED symptom-related HCU was assessed using a multiplechoice question about healthcare sought for an emotional or mental health problem. The 12 sources listed included general or family practitioner, psychologist, psychiatrist, counsellor, social or welfare worker, dietician or nutritionist, naturopath or other alternative therapist, community mental health worker/team, self-help support group, commercial weight-loss programme, friend or family member. The next question asked: Have you spoken to or sought advice from any of these people specifically in relation to a problem with your eating, such as eating too much in one go, feeling that your eating is out of control, being preoccupied with what you can eat or when you can eat, or with burning up calories, or other problems 


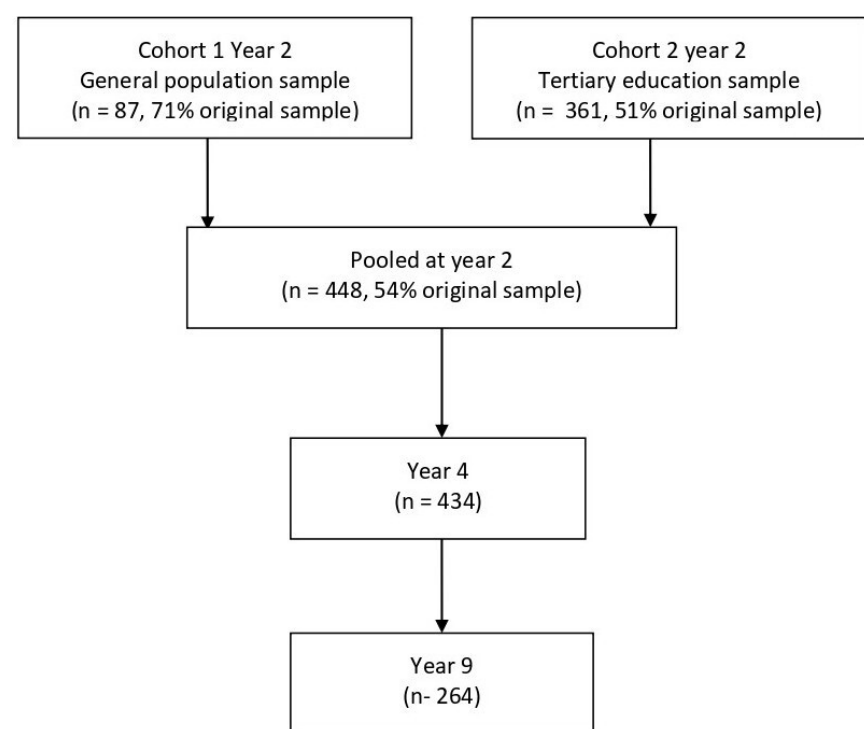

Figure 1 Flow of participants meeting eligibility for the present study.

like this? If yes, which people? The results of the second question were then grouped into healthcare providers who potentially formed part of an evidence-based care appropriate for an ED issue (ie, general practitioner, psychologist, psychiatrist); others, for example, social or welfare worker and none for descriptive analysis, and into binary categories of any HCU or no HCU for regression analysis. If a participant had engaged with multiple types of support, they were allocated to the highest (most ED appropriate) level of HCU.

\section{Mental health literacy}

MHL was assessed using a vignette describing a young girl with $\mathrm{BN}$, including the core clinical features while avoiding medical terms. Participants were asked to select her 'main problem' from a randomly ordered list that included AN, BN, ED, depression, low self-esteem, poor diet and 'no real problem', among others. They were then asked to select the most helpful professional and most helpful treatment from randomly ordered lists. These three measures of MHL were coded into binary yes/no variables for analysis, according to whether they identified appropriate problems and interventions. This survey was developed by Mond based on Jorm et al. ${ }^{44}$

\section{ED symptom severity}

ED symptom severity was measured using the EDE Questionnaire (EDE-Q), a 28-item survey adapted from the EDE interview. The EDE-Q assesses ED symptoms in the preceding month, using a 7-point scale for 22 items used to calculate a global score. The EDE-Q has been found to have good test-retest and inter-rater reliability, internal consistency and criterion and construct validity in international and Australian clinical and non-clinical samples. ${ }^{48-50}$ In the present study, internal consistency at baseline was good with an alpha of 0.93 for the 22 items used in the global score.
Mental health-related quality of life

MHRQoL was assessed using the Short Form-12 (SF-12) Health Status Questionnaire (SF-12), a 12-item questionnaire assessing self-reported physical and psychological symptoms as well as impact on functioning, producing a Physical and a Mental Component Summary Score. The SF-12 has been subjected to extensive validity testing ${ }^{51}$ and demonstrated its validity and utility in assessing both physical and mental health status, with high reliability of test-retest correlations in physical and mental health in clinical and non-clinical samples ${ }^{5152}$ as well as acceptable (alpha $=0.80)$ internal consistency and convergent validity and strong predictive validity and sensitivity to changes in an ED clinical sample..$^{53}$ An additional measure of role impairment was asked at year 2. This was a single question: 'On how many days were you more likely to have been unable to complete your work, study or household responsibilities in the preceding 4 weeks because of a problem with your physical or mental health'. In the present study, the alpha at baseline was acceptable at 0.71 .

\section{Psychological distress}

Psychological distress was assessed using the Kessler Psychological Distress Scale (K-10). The questionnaire consists of 10 questions assessing self-reported distress associated with symptoms of depression and anxiety, each scored on a 5-point scale. Following international studies and demonstrated criterion and construct validity with high internal consistency (eg, Kessler et $a \tilde{p}^{\tilde{4}}$ ). The K-10 has been validated as a screening tool which can discriminate well between mood and anxiety disorders. ${ }^{55}$ In the present study, the alpha at baseline was 0.94 .

\section{Statistical analysis}

Data were cleaned and new variables were derived as above. Data were inspected for normality and descriptive statistics was used to present participant features and HCU. Between-group differences were tested with univariate statistics such as the t-test or Mann-Whitney $\mathrm{U}$ test or $\chi^{2}$ test as appropriate to the data, $\mathrm{p}<0.05$. For estimating the effect of HCU on a continuous outcome variable measured over time, including mental health quality of life, ED symptom severity and overall mental health, the repeated measures linear mixed-effects regression was used. For estimating the effect of HCU on a binary outcome variable measured over time, such as identifying the appropriate MHL professional or MHL problem or MHL treatment, repeated measures logistic mixed-effects regression was used. All regression models controlled for the effects of baseline (year 2) body mass index (BMI), age, education, and work status. The predictive performance of the mixed effects models was assessed by $R^{2}$ when the outcome variable is continuous ${ }^{56}$ and by pseudo $R^{2}$ when the outcome variable is dichotomous. ${ }^{57}$ Multiple imputations were performed to account for missing observations in all statistical analyses. The number of imputations performed was 25. All results were pooled using Rubin's rules ${ }^{58}$ Effect size for a continuous outcome variable was 
estimated by Cohen's d with small, moderate and strong effects as $0.20-0.49,0.5-0.79$ and $0.8-1.00$, respectively; while for a categorical (dichotomous) outcome variable by OR with small, moderate, large and very large effects as 1.5-2.49, 2.5-3.99, 4-9.99, 10 and above, respectively. ${ }^{59}$ Descriptive analysis was performed with SPSS V.25, ${ }^{60}$ while all regression analyses were performed using SAS V.9.4. ${ }^{61}$

This was a nested study, so power analyses were retrospective. For multiple linear regression with the lowest estimated Cohen's d of 0.27438 for MHRQoL, assuming alpha $=0.05, \mathrm{R}^{2}$ difference $=0.0119$ for including MHRQoL and total $R^{2}=0.10$, power $=0.80$, sample size is 596 . Again for multiple linear regression with the lowest estimated Cohen's d of 0.27438 for MHRQoL, and assuming alpha $=0.05, \mathrm{R}^{2}$ difference $=0.0119$ for including MHRQoL and total $R^{2}=0.20$, power $=0.80$, sample size is 530 . So, the required sample size for multiple linear regression ranges from 530 to 596 for alpha $=0.05$, power $=0.80$. As this study has sample size of 1344, a clinically significant effect size of HCU for the outcome MHRQOL, which is much lower than that of 0.27438 (as estimated by multiple linear regression) can be detected as statistically significant. For logistic regression with the lowest estimated OR of 1.05632 for MHL person, alpha $=0.05$, pseudo $\mathrm{R}^{2}=0.1$ and power $=0.80$, we need a sample size of 8580 . For logistic regression with the lowest estimated OR of 1.05632 for HCU and MHL person, alpha $=0.05$, pseudo $\mathrm{R}^{2}=0.2$ and power $=0.80$, sample size is 9652 . So the required sample size for logistic regression to detect an OR of 1.05632 for HCU and MHL person ranges from 8580 to 9652 for

Table 1 Demographic and other features of participants in year 2 (baseline) and with regards to their Health Care Use (HCU)

\begin{tabular}{|c|c|c|c|c|c|}
\hline & Total & HCU year 2 & No HCU year 2 & Statistic (df) & $P$ value \\
\hline & Mean (SE) & & & $t(d f)$ & \\
\hline $\begin{array}{l}\text { Age (years) } \\
\mathrm{N}=443\end{array}$ & $30.6(0.4)$ & $30.12(1.0)$ & $30.8(0.6)$ & $0.53(438)$ & 0.599 \\
\hline $\begin{array}{l}\mathrm{BMI}\left(\mathrm{kg} / \mathrm{m}^{2}\right) \\
\mathrm{N}=432\end{array}$ & $25.4(0.3)$ & $27.4(0.8)$ & $24.9(0.3)$ & $-3.72(427)$ & $<0.001$ \\
\hline $\begin{array}{l}\text { Eating disorder } \\
\text { symptom (EDE-Q } \\
\text { global) } N=426\end{array}$ & $2.0(0.1)$ & $2.9(0.2)$ & $1.8(0.1)$ & $-6.62(421)$ & $<0.001$ \\
\hline $\begin{array}{l}\text { Psychological distress } \\
(\mathrm{K}-10) \mathrm{N}=441\end{array}$ & $18.7(0.3)$ & $21.8(0.8)$ & $17.8(0.4)$ & $-4.94(436)$ & $<0.001$ \\
\hline MHRQoL (SF-12) & $43.5(0.1)$ & $40.7(1.3)$ & $44.4(0.6)$ & $2.55(433)$ & 0.011 \\
\hline
\end{tabular}

$\mathrm{N}=438$

\begin{tabular}{|c|c|c|c|c|c|}
\hline \multicolumn{3}{|c|}{ Med (IQR) } & \multicolumn{3}{|c|}{ Mann-Whitney U } \\
\hline Role impairment & $1.0(3.5)$ & $2.0(5.5)$ & $0(3.0)$ & -4.254 & $<0.001$ \\
\hline Married & $203(45.7 \%)$ & $39(43.8 \%)$ & $164(46.2 \%)$ & $0.16(2)$ & 0.687 \\
\hline Children: yes & 149 (33.7\%) & $31(34.8 \%)$ & $118(33.4 \%)$ & $0.063(1)$ & 0.802 \\
\hline Not employed & $45(10.11 \%)$ & $13(14.6 \%)$ & $32(9.0 \%)$ & & \\
\hline Part time/casual & $68(15.3 \%)$ & $15(16.9 \%)$ & $53(14.9 \%)$ & & \\
\hline Full time & $163(36.6 \%)$ & $29(32.6 \%)$ & $134(37.6 \%)$ & & \\
\hline $\begin{array}{l}\text { Highest level of } \\
\text { education }\end{array}$ & & & & $0.338(2)$ & 0.844 \\
\hline $\begin{array}{l}\text { Bachelor or } \\
\text { postgraduate degree }\end{array}$ & 195 (43.9\%) & $37(41.6 \%)$ & $158(44.5 \%)$ & & \\
\hline MHL person: yes & $234(53.8 \%)$ & $49(56.3 \%)$ & $183(53.0 \%)$ & $0.300(1)$ & $0.631^{*}$ \\
\hline MHL main problem: yes & $70(15.7 \%)$ & $21(23.65)$ & 47 (13.2\%) & $5.884(1)$ & $0.021^{\star}$ \\
\hline MHL treatment: yes & $280(65 \%)$ & $53(62.4 \%)$ & $227(62.2 \%)$ & $0.441(1)$ & $0.526^{*}$ \\
\hline
\end{tabular}

The significnat levels ( $\mathrm{p}$ values) are provided in bold.

*Fisher exact test.

BMI, body mass index; EDE-Q, Eating Disorder Examination Questionnaire; K-10, Kessler Psychological Distress Scale; MHL, mental health literacy; identified 'main problem' of eating disorder or other, most appropriate helpful professional and treatment/interventions; MHRQoL, mental health-related quality of life; SF, Short Form. 


\begin{tabular}{|c|c|c|c|}
\hline & $\begin{array}{l}\text { Year } 2 \\
(\mathrm{~N}=445) ; \\
\text { missing=3 }\end{array}$ & $\begin{array}{l}\text { Year } 4 \\
(\mathrm{~N}=350) ; \\
\text { missing=98 }\end{array}$ & $\begin{array}{l}\text { Year } 9 \\
(\mathrm{~N}=257) ; \\
\text { missing }=191\end{array}$ \\
\hline & N (\%) & & \\
\hline $\begin{array}{l}\mathrm{HCU} \text { emotional or } \\
\text { mental problem }\end{array}$ & 212 (47.6) & $170(48.3)$ & $136(52.7)$ \\
\hline $\begin{array}{l}\text { HCU eating } \\
\text { specifically }\end{array}$ & $89(20.0)$ & $58(16.6)$ & 35 (13.6) \\
\hline $\begin{array}{l}\text { Evidence-based } \\
\text { care provider }\end{array}$ & $39(8.8)$ & $25(7.1)$ & $15(5.8)$ \\
\hline Other & 50 (11.2) & $33(9.4)$ & $20(7.8)$ \\
\hline None & $356(80)$ & $292(83.4)$ & $222(86.4)$ \\
\hline $\begin{array}{l}\text { Intending on } \mathrm{HCU} \\
\text { for emotional, } \\
\text { mental health or } \\
\text { eating problem in } \\
\text { next } 12 \text { months }\end{array}$ & 118 (26.5) & 91 (26.5) & 66 (26.6) \\
\hline
\end{tabular}

alpha $=0.05$, power $=0.80$. As this study has a much smaller sample size of 896 , for logistic regression this means that a clinically significant effect size of HCU for the outcome 'MHL person', which is much higher than that of 1.05632 (as estimated by multiple linear regression), would be detected as statistically significant.

\section{Patient and public involvement}

There was no direct patient or public involvement when this study was first designed in 2004/2005. Participants have been kept informed of study outcomes over time with yearly newsletters from the research team.

\section{RESULTS}

\section{Sample characteristics}

Demographic and other features are shown in table 1 . Those who sought help at year 2 were significantly more likely to have a higher BMI, higher levels of ED symptoms and psychological distress, lower MHRQoL, higher role impairment and better MHL with regards to identifying an ED problem, compared with those who did not seek help. There were no significant differences in other demographic features or outcomes between groups based on HCU at year 2.

\section{Types of healthcare accessed}

As shown in table 2, approximately half of the sample accessed healthcare for an emotional or mental problem at each of the three time points. The proportion that sought help specifically for eating decreased over time. Of those who sought help, the majority consistently accessed healthcare services that were not considered evidencebased ED appropriate sources of help. The proportion of the sample that intended to access healthcare for a mental health of eating problem in the following year was consistent across time points (table 2).
Table 3 Regression results for the effect of year 2 Health Care Use (HCU) on eating disorder symptoms, psychological distress, mental health-related quality of life and mental health literacy

\section{Independent variable*}

Health Care Use (HCU) in year 2†¥

\begin{tabular}{|c|c|c|}
\hline $\begin{array}{l}\text { Dependent } \\
\text { variable§ }\end{array}$ & $\begin{array}{l}\text { Effect size- } \\
\text { Cohen's d ( } p \text { value) }\end{array}$ & $\begin{array}{l}\text { Model fit } \mid-R^{2} \text { or } \\
\text { pseudo } R^{2} \S\end{array}$ \\
\hline EDEQ global & $-0.45(<0.0001)$ & $41.97 \%$ \\
\hline $\begin{array}{l}\text { Mental health-related } \\
\text { quality of life (SF12) }\end{array}$ & $0.27(<0.0001)$ & $35.96 \%$ \\
\hline $\begin{array}{l}\text { Psychological } \\
\text { distress (K10) }\end{array}$ & $-0.40(<0.0001)$ & $32.18 \%$ \\
\hline \multicolumn{3}{|c|}{ OR (p value) } \\
\hline MHL person: yes & $1.18(0.6640)$ & $39.98 \%$ \\
\hline $\begin{array}{l}\text { MHL main problem: } \\
\text { yes }\end{array}$ & $1.45(0.0860)$ & $42.24 \%$ \\
\hline MHL treatment: yes & $1.17(0.9356)$ & $42.42 \%$ \\
\hline
\end{tabular}

The significnat levels ( $p$ values) are provided in bold.

${ }^{*}$ All regression models controlled for the effects of baseline (year 2) BMI, age, education and work status.

†For $\mathrm{HCU}$ in year 2, the estimated effect is for those seeking help for an eating-related problem in year 2 .

$\ddagger$ For $\mathrm{HCU}$ in year 2, the reference category is for those who did not seek help for an eating-related problem in year 2 . $\S$ Mental health-related quality of life, eating disorder symptoms and psychological distress were measured at years 4 and 9; $\mathrm{MHL}$ was measured at year 4 only.

$\eta R^{2}$ was estimated for models predicting EDEQ global, mental health-related quality of life, psychological distress while pseudo $\mathrm{R}^{2}$ was estimated for models predicting MHL person, MHL problem and $\mathrm{MHL}$ treatment.

BMI, body mass index; EDE-Q, Eating Disorder Examination Questionnaire; K-10, Kessler Psychological Distress Scale; $\mathrm{MHL}$, mental health literacy; identified 'main problem' of eating disorder or other, most appropriate helpful professional and treatment/interventions; SF, Short Form.

Year 2 HCU and ED symptom severity, MHRQoL, psychological distress (K-10) from year 2 to year 4 and year 9 and MHL from year 2 to year 4

Effects of year 2 HCU on ED symptoms, psychological distress, MHRQoL and MHL are shown in table 3. Exposure to healthcare at baseline was significantly associated with a decrease in EDEQ global score indicating an improvement in ED symptoms; an increase in SF12 scores indicating improved mental health quality of life and a decrease in K10 scores reflecting a decrease in psychological distress. The effect sizes associated with exposure to HCU at baseline and the outcomes are all numerically small in magnitude according to Rosenthal's criteria ${ }^{59}$ (table 3).

Individuals exposed to healthcare at baseline were more likely over time to correctly identify an ED, the appropriate professional from whom to seek help and an appropriate treatment for an ED, based on a clinical vignette. However, while these results were in the expected direction, none was statistically significant $(\mathrm{p}>0.05)$. The effect sizes are all very small $(1 \leq \mathrm{OR}<1.5)$ 
for the MHL outcomes based on Rosenthal's criteria. ${ }^{59}$ The effect sizes are also very small $(0.20 \leq$ Cohen's $d \leq 0.49)$ for EDEQ global, MHRQoL and psychological distress. The predictive ability of the fitted models ranged from $32.18 \%$ to $42.42 \%$ for psychological distress and MHL treatment, respectively.

\section{DISCUSSION}

\section{Principal findings - types of HCU and outcomes over time}

The present paper found that the rate of ED-specific HCU was low, at less than $20 \%$ in a symptomatic sample (ie, with higher levels of ED symptoms and psychological distress and poorer MHRQoL compared with young women in the general population of Australia ${ }^{62}$ ) of adult community women. Further, it was found that the majority of help seeking was not for 'first-line' professional healthcare and that ED symptom severity improved over time with HCU. These findings are consistent with the Hart $e t a l{ }^{\prime}{ }^{19}$ systematic review that found low rates of ED help seeking among community people with ED. ${ }^{19}$ To our knowledge, this is also the first paper to extend this area of research to explore the effects over time of HCU on ED health literacy in addition to symptoms and quality of life outcomes.

The improvement in ED symptoms, decreased psychological distress and improved MHRQoL over time with HCU supports previous literature regarding the effectiveness of both social support and professional medical services in improving ED recovery. ${ }^{64-68}$ There was a diversity of non-specialist HCU that included professionals such as dietitians as well as alternative therapies such as naturopathy and commercial weight loss programmes. This and other studies and case reports ${ }^{69} 70$ suggest that these nonprofessional services may be popular but, as outlined by Insel, ${ }^{71}$ empirical research is imperative to the translation of their role in the management of people with EDs. This could, for instance, include evaluation of community-lead help and services such as in Australia from The Butterfly Foundation (an ED advocacy and support organisation), which has a national 'free' EDHope telephone line for anyone seeking help or further information about EDs. Further, these interventions may improve general psychological health status (ie, decreased psychological distress and improved MHRQoL) particularly as people with EDs often have psychological comorbidities such as anxiety and depression. ${ }^{38-41}$ Such known comorbidity is consistent with our finding of a high rate of help seeking by people with EDs for other emotional problems.

The present study also found that help seeking in people with an ED was higher in those with a higher BMI at baseline. This was likely because they were also seeking help for weight loss and comorbidities. Former studies have demonstrated that health services accessed by individuals with EDs tend to be those geared towards weight management, rather than disordered eating. ${ }^{19} 367273$ While this could suggest that HCU may not lead to an improvement in ED symptoms, this study demonstrates that ED symptom-related HCU, regardless of whether weight loss or ED treatment was the goal, is associated with improvement in ED symptoms and overall mental health. This may suggest that management of the comorbidities and complications of EDs, including high BMI, is also an important aspect of ED treatment.

\section{Healthcare use and eating disorder mental health literacy}

HCU was not associated with a significant improvement in MHL. This may reflect the diversity of help sought, particularly as many participants sought social rather than professional support. Social support may improve professional help seeking; Smalec et al's study of individuals with $\mathrm{BN}$ currently seeking help found that $64 \%$ of their sample cited social encouragement as a contributing factor to their help seeking. ${ }^{24}$ In light of these findings, interventions to improve the MHL of the broader population may be beneficial in improving the MHL and subsequent help seeking of those with EDs. Informational interventions such as Mental Health First Aid ${ }^{74} 75$ and online education modules ${ }^{76}$ have been identified as effective interventions to improve MHL, which is associated with improved help seeking and QOL. ${ }^{37}$ This study supports the need for further empirical research into these and other interventions.

\section{Strengths and limitations}

This study relied on self-report instruments, however, these were well validated which is a strength. Further strengths of the study are the large sample size and longitudinal design. There was moderate attrition over time, for which multiple imputation, which is the state-of-the-art method to handle missing data, was employed and this is a further strength of the study. The study limitations include not being representative of the general population, particularly with regards to men, older people and a higher proportion having attained tertiary-level education. The MHL tool was old and its use of forced-choice questions in a self-report format is inevitably associated with a loss of information and problems of interpretation. Other limitations with this method of assessment are the tendency for participants to avoid the most extreme options in responding to certain questions, and unknown effects of 'social desirability' on responses. ${ }^{78-80}$ Furthermore, the study did not compare the outcomes of different types of help seeking; we can therefore not draw conclusions regarding which particular type of healthcare was most beneficial in this study; this is an important direction for future research. Finally, there was an inability to estimate in regression analysis, the interactions between year $2 \mathrm{HCU}$ and time due to inadequate power to perform such analysis. At the design stage, the study was powered to detect main effects (eg, for year 2 $\mathrm{HCU}$ ) but not for interaction effects. The retrospective power analysis also showed that for outcomes of psychological distress (K10), MHRQoL and the global EDE-Q score, the study had enough power to detect any significant effect of HCU but not for the three MHL outcomes. 


\section{Clinical implications}

The clinical implications of this study are that health services may need to improve efforts and develop specific approaches to increase patients' MHL, as MHL demonstrably did not improve with HCU. Such interventions include the wider propagation of ED First $\mathrm{Aid}^{75}$; this may increase the capacity of individuals' social support systems to better assist them in management of their ED. Furthermore, the potential utility of a wider range of services in management of EDs should be considered by clinicians, in particular, encouraging patients to seek social support from friends and family may be beneficial.

\section{Conclusions and future directions}

This study demonstrated that individuals with EDs accessed healthcare that was not evidence based more often than that which was. However, the HCU was associated with an improvement in ED symptoms, MHRQoL and psychological distress. This suggests the utility of a variety of specialist, social and other professional or alternative services in ED management and facilitating recovery from EDs. Research into the specific and non-specific effects, particularly mediators of effects, of alternative and nonspecialist therapies is thus important. Furthermore, the role of weight management in addressing EDs associated with increased weight should be further explored.

Contributors NH was responsible for design of the study, data cleaning, descriptive and univariate analytic statistics and writing the manuscript. HM was responsible for design of the longitudinal statistical analyses and their presentation in the paper. NF was responsible for data management. PH was responsible for advising on study design, the overall collection of data from the two pooled cohorts, advising on statistical methods, editorial review of the paper. All authors read and approved the final paper.

Funding The first 5 years of this study received funding to author $\mathrm{PH}$ from an Australian Rotary Health Project Grant 2006-2008.

Competing interests $\mathrm{PH}$ has received in sessional fees from the Australian Medical Council, Therapeutic Guidelines, and New South Wales Institute of Psychiatry, royalties from Hogrefe and Huber, McGraw Hill Education and Blackwell Scientific Publications, and research grants from the NHMRC and ARC. She is Chair of the National Eating Disorders Collaboration in Australia. In July 2017, she provided a commissioned report for Shire Pharmaceuticals and in 2018/2019 received honoraria for education of psychiatrists.

\section{Patient consent for publication Not required.}

Ethics approval This study was approved by the Human Research Ethics Committee of the universities originally involved, with Western Sydney University as lead committee (approval number 07/240). Follow-up surveys were approved by a second ethics application from Western Sydney University (approval number H9283). Informed consent was acquired at each time point when participants completed the survey.

Provenance and peer review Not commissioned; externally peer reviewed.

Data availability statement Data are available upon reasonable request. Data (deidentified) are currently auspiced by the Western Sydney University Human Research Ethics Committee and are available for collaborative studies from the corresponding author upon request and ethic approval. http://orcid.org/0000-00030296-6856.

Open access This is an open access article distributed in accordance with the Creative Commons Attribution Non Commercial (CC BY-NC 4.0) license, which permits others to distribute, remix, adapt, build upon this work non-commercially, and license their derivative works on different terms, provided the original work is properly cited, appropriate credit is given, any changes made indicated, and the use is non-commercial. See: http://creativecommons.org/licenses/by-nc/4.0/.
ORCID iD

Phillipa Hay http://orcid.org/0000-0003-0296-6856

\section{REFERENCES}

1 American Psychiatric Association. Diagnostic and statistical manual of mental disorders (DSM-5®). American Psychiatric Pub 2013;329.

2 Galmiche M, Déchelotte P, Lambert G, et al. Prevalence of eating disorders over the 2000-2018 period: a systematic literature review. Am J Clin Nutr 2019;109:1402-13.

3 Katzman DK. Medical complications in adolescents with anorexia nervosa: a review of the literature. Int J Eat Disord 2005;37 Suppl:S52-9.

4 Zipfel S, Lowe B, Herzog W. Medical complications. In: Treasure J, Schmidt U, eds. Handbook of eating disorders. Chichester. UK: John Wiley \& Sons Ltd, 2003: 191-206.

5 Begg S, Vos T, Barker B, et al. The burden of disease and injury in Australia 2003. Phe 82. Canberra: Australian Institute of health and welfare, 2007. Available: https://www.aihw.gov.au/getmedia/ f81b92b3-18a2-4669-aad3-653aa3a9f0f2/bodaiia03.pdf. aspx[Accessed 10 Jan 2019].

6 Agras WS. The consequences and costs of the eating disorders. Psychiatr Clin North Am 2001;24:371-9.

7 Pearlstein T. Eating disorders and comorbidity. Arch Womens Ment Health 2002;4:67-78.

8 Padierna A, Quintana JM, Arostegui I, et al. The health-related quality of life in eating disorders. Qual Life Res 2000;9:667-74.

9 Mond JM, Hay PJ, Rodgers B, et al. Assessing quality of life in eating disorder patients. Qual Life Res 2005;14:171-8.

10 Fischer S, le Grange D. Comorbidity and high-risk behaviors in treatment-seeking adolescents with Bulimia nervosa. Int J Eat Disord 2007; 40:751-3.

11 Sansone RA, Levitt JL. Self-Harm behaviors among those with eating disorders: an overview. Eat Disord 2002;10:205-13.

12 Koutek J, Kocourkova J, Dudova I. Suicidal behavior and selfharm in girls with eating disorders. Neuropsychiatr Dis Treat 2016;12:787-93.

13 Darby A, Hay P, Mond J, et al. Disordered eating behaviours and cognitions in young women with obesity: relationship with psychological status. Int J Obes 2007;31:876-82.

14 Mond J, Rodgers B, Hay P, et al. Disability associated with community cases of commonly occurring eating disorders. Aust N Z $J$ Public Health 2004;28:246-51.

15 Guyatt GH, Feeny DH, Patrick DL. Measuring health-related quality of life. Ann Intern Med 1993;118:622-9.

16 Hay P, Mitchison D, Collado AEL, et al. Burden and health-related quality of life of eating disorders, including Avoidant/Restrictive food intake disorder (ARFID), in the Australian population. J Eat Disord 2017;5.

17 de la Rie SM, Noordenbos G, van Furth EF, et al. Quality of life and eating disorders. Qual Life Res 2005;14:1511-21.

18 Bosanac P, Kurlender S, Stojanovska L, et al. Neuropsychological study of underweight and "weight-recovered" anorexia nervosa compared with bulimia nervosa and normal controls. Int J Eat Disord 2007;40:613-21.

19 Hart LM, Granillo MT, Jorm AF, et al. Unmet need for treatment in the eating disorders: a systematic review of eating disorder specific treatment seeking among community cases. Clin Psychol Rev 2011;31:727-35.

20 Hay P, Chinn D, Forbes D, et al. Royal Australian and New Zealand College of Psychiatrists clinical practice guidelines for the treatment of eating disorders. Aust N Z J Psychiatry 2014;48:977-1008.

21 National Institute for Health and Care Excellence. Eating disorders: recognition and treatment. NICE, 2017. https://www.nice.org.uk/ guidance/ng69

22 Leonidas C, Dos Santos MA. Social support networks and eating disorders: an integrative review of the literature. Neuropsychiatr Dis Treat 2014;10:915.

23 Linville D, Brown T, Sturm K, et al. Eating disorders and social support: perspectives of recovered individuals. Eat Disord 2012;20:216-31.

24 Smalec JL, Klingle RS. Bulimia interventions via interpersonal influence: the role of threat and efficacy in persuading bulimics to seek help. J Behav Med 2000;23:37-57.

25 Akey JE, Rintamaki LS, Kane TL. Health belief model deterrents of social support seeking among people coping with eating disorders. J Affect Disord 2013;145:246-52.

26 Dolan B, Lieberman S, Evans C, et al. Family features associated with normal body weight Bulimia. Int J Eat Disord 1990;9:639-47.

27 Limbert C. Perceptions of social support and eating disorder characteristics. Health Care Women Int 2010;31:170-8. 
28 Ogg EC, Millar HR, Pusztai EE, et al. General practice consultation patterns preceding diagnosis of eating disorders. Int J Eat Disord 1997;22:89-93.

29 Striegel-Moore RH, DeBar L, Wilson GT, et al. Health services use in eating disorders. Psychol Med 2008;38:1465-74.

30 Cachelin FM, Veisel C, Barzegarnazari E, et al. Disordered eating, acculturation, and treatment-seeking in a community sample of Hispanic, Asian, black, and white women. Psychol Women Q 2000;24:244-53.

31 Mond JM, Hay PJ, Rodgers B, et al. Health service utilization for eating disorders: findings from a community-based study. Int $J$ Eat Disord 2007;40:399-408.

32 Mond JM, Myers TC, Crosby RD, et al. Bulimic eating disorders in primary care: hidden morbidity still? J Clin Psychol Med Settings 2010;17:56-63.

33 Mond JM, Hay PJ, Darby A, et al. Women with bulimic eating disorders: when do they receive treatment for an eating problem? J Consult Clin Psychol 2009;77:835-44.

34 Palavras MA, Hay PJ, Lujic S, et al. Comparing symptomatic and functional outcomes over 5 years in two nonclinical cohorts characterized by binge eating with and without objectively large episodes. Int J Eat Disord 2015;48:1158-65.

35 Griffiths S, Mond JM, Murray SB, et al. The prevalence and adverse associations of stigmatization in people with eating disorders. Int $J$ Eat Disord 2015;48:767-74.

36 Evans EJ, Hay PJ, Mond J, et al. Barriers to help-seeking in young women with eating disorders: a qualitative exploration in a longitudinal community survey. Eat Disord 2011;19:270-85.

37 Hay P, Mond J, Paxton S, et al. What are the effects of providing evidence-based information on eating disorders and their treatments? A randomized controlled trial in a symptomatic community sample. Early Interv Psychiatry 2007;1:316-24.

38 Oakley Browne MA, Wells JE, McGee MA, et al. Twelve-month and lifetime health service use in te Rau Hinengaro: the New Zealand mental health survey. Aust N Z J Psychiatry 2006;40:855-64.

39 Hudson JI, Hiripi E, Pope HG, et al. The prevalence and correlates of eating disorders in the National comorbidity survey replication. Biol Psychiatry 2007;61:348-58.

40 Jacobi F, Wittchen $\mathrm{H}-\mathrm{U}$, Hölting $\mathrm{C}$, et al. Prevalence, co-morbidity and correlates of mental disorders in the general population: results from the German health interview and examination survey (GHS). Psychol Med 2004;34:597-611.

41 Bijl RV, Ravelli A. Psychiatric morbidity, service use, and need for care in the general population: results of the Netherlands mental health survey and incidence study. Am J Public Health 2000;90:602.

42 Andrews G, Sanderson K, Slade T, et al. Why does the burden of disease persist? relating the burden of anxiety and depression to effectiveness of treatment. Bull World Health Organ 2000;78:A3-54.

43 Jorm AF, Angermeyer M, Katschnig H. Public knowledge of and attitudes to mental disorders: A limiting factor in the optimal use of treatment services. In: Andrews G, Henderson S, eds. Unmet need in psychiatry. Cambridge: Cambridge University Press, 2000: 399-413.

44 Jorm AF, Korten AE, Jacomb PA, et al. "Mental health literacy": a survey of the public's ability to recognise mental disorders and their beliefs about the effectiveness of treatment. Med J Aust 1997;166:182-6.

45 Mond JM, Hay PJ, Paxton SJ, et al. Eating disorders "mental health literacy" in low risk, high risk and symptomatic women: implications for health promotion programs. Eat Disord 2010;18:267-85.

46 Mitchison D, Crino R, Hay P. The presence, predictive utility, and clinical significance of body dysmorphic symptoms in women with eating disorders. J Eat Disord 2013;1:20.

47 Mitchison D, Morin A, Mond J, et al. The bidirectional relationship between quality of life and eating disorder symptoms: a 9year community-based study of Australian women. PLoS One 2015;10:e0120591.

48 Mond JM, Hay PJ, Rodgers B, et al. Validity of the eating disorder examination questionnaire (EDE-Q) in screening for eating disorders in community samples. Behav Res Ther 2004;42:551-67.

49 Mond JM, Hay PJ, Rodgers B, et al. Temporal stability of the eating disorder examination questionnaire. Int $J$ Eat Disord 2004;36:195-203.

50 Berg KC, Peterson CB, Frazier P, et al. Psychometric evaluation of the eating disorder examination and eating disorder examinationquestionnaire: a systematic review of the literature. Int $J$ Eat Disord 2012;45:428-38.

51 Ware J, Kosinski M, Keller SD. A 12-Item short-form health survey: construction of scales and preliminary tests of reliability and validity. Med Care 1996;34:220-33.

52 Al Omari O, Alkhawaldeh A, ALBashtawy M, et al. A review of the short form health Survey-Version 2. J Nurs Meas 2019;27:77-86.
53 Mitchison D, Hay P, Engel S, et al. Assessment of quality of life in people with severe and enduring anorexia nervosa: a comparison of generic and specific instruments. BMC Psychiatry 2013;13:284.

54 Kessler RC, Barker PR, Colpe LJ, et al. Screening for serious mental illness in the general population. Arch Gen Psychiatry 2003;60:184-9.

55 Furukawa TA, Kessler RC, Slade T, et al. The performance of the K6 and K10 screening scales for psychological distress in the Australian national survey of mental health and well-being. Psychol Med 2003;33:357-62.

56 Edwards LJ, Muller KE, Wolfinger RD, et al. An R2 statistic for fixed effects in the linear mixed model. Stat Med 2008;27:6137-57. I.

57 Nakagawa S, Schielzeth H. A general and simple method for obtaining $R 2$ from generalized linear mixed-effects models. Methods in Ecology and Evolution 2012;4.

58 Rubin DB. Multiple imputation for nonresponse in surveys. New York: John Wiley and Sons, 1987.

59 Rosenthal JA. Qualitative descriptors of strength of association and effect size. J Soc Serv Res 1996;21:37-59.

60 IBM Corp. Ibm SPSS statistics for windows, version 25.0. Armonk, NY: IBM Corp, 2017.

61 SAS Institute Inc. Sas version 9.4. Cary, NC, USA: SAS Institute, 2013.

62 Mond JM, Hay PJ, Rodgers B, et al. Eating disorder examination questionnaire (EDE-Q): norms for young adult women. Behav Res Ther 2006;44:53-62.

63 Andrews G, Slade T. Interpreting scores on the Kessler psychological distress scale (K10). Aust N Z J Public Health 2001;25:494-7

64 Bertera EM. Mental health in U.S. adults: the role of positive social support and social negativity in personal relationships. J Soc Pers Relat 2005;22:33-48.

65 Hay PP, Bacaltchuk J, Stefano S, et al. Psychological treatments for Bulimia nervosa and binging. Cochrane Database Syst Rev 2009;4:CD000562.

66 Hay P. A systematic review of evidence for psychological treatments in eating disorders: 2005-2012. Int J Eat Disord 2013;46:462-9.

67 Bulik CM, Berkman ND, Brownley KA, et al. Anorexia nervosa treatment: a systematic review of randomized controlled trials. Int $J$ Eat Disord 2007;40:310-20.

68 Brownley KA, Berkman ND, Sedway JA, et al. Binge eating disorder treatment: a systematic review of randomized controlled trials. Int $J$ Eat Disord 2007;40:337-48

69 Birmingham CL, Sidhu FK. Complementary and alternative medical treatments for anorexia nervosa: case report and review of the literature. Eat Weight Disord 2007;12:e51-3.

70 Mclver S, O'Halloran P, McGartland M. Yoga as a treatment for binge eating disorder: a preliminary study. Complement Ther Med 2009;17:196-202.

71 Insel TR. Translating scientific opportunity into public health impact: a strategic plan for research on mental illness. Arch Gen Psychiatry 2009;66:128-33

72 Hay PJ, Marley J, Lemar S. Covert eating disorders: the prevalence, characteristics and help-seeking of those with bulimic eating disorders in general practice. Primary Care Psychiatry 1998;4:95-9.

73 Cachelin FM, Rebeck R, Veisel C, et al. Barriers to treatment for eating disorders among ethnically diverse women. Int J Eat Disord 2001;30:269-78.

74 Bond KS, Jorm AF, Kitchener BA, et al. Mental health first aid training for Australian medical and nursing students: an evaluation study. BMC Psychol 2015;3:11-20.

75 Hart LM, Jorm AF, Paxton SJ. Mental health first aid for eating disorders: pilot evaluation of a training program for the public. BMC Psychiatry 2012;12:98.

76 Sebastian J, Richards D. Changing stigmatizing attitudes to mental health via education and contact with embodied conversational agents. Comput Human Behav 2017;73:479-88.

77 Taylor-Rodgers E, Batterham PJ. Evaluation of an online psychoeducation intervention to promote mental health help seeking attitudes and intentions among young adults: randomised controlled trial. J Affect Disord 2014;168:65-71.

78 Mond JM, Hay PJ, Rodgers B, et al. Beliefs of the public concerning the helpfulness of interventions for Bulimia nervosa. Int $J$ Eat Disord 2004;36:62-8.

79 Mond JM, Hay PJ, Rodgers B, et al. Beliefs of women concerning the severity and prevalence of Bulimia nervosa. Soc Psychiatry Psychiatr Epidemiol 2004;39:299-304.

80 Mond JM, Hay PJ, Rodgers B, et al. Beliefs of women concerning causes and risk factors for Bulimia nervosa. Aust $N Z J$ Psychiatry 2004;38:463-9. 